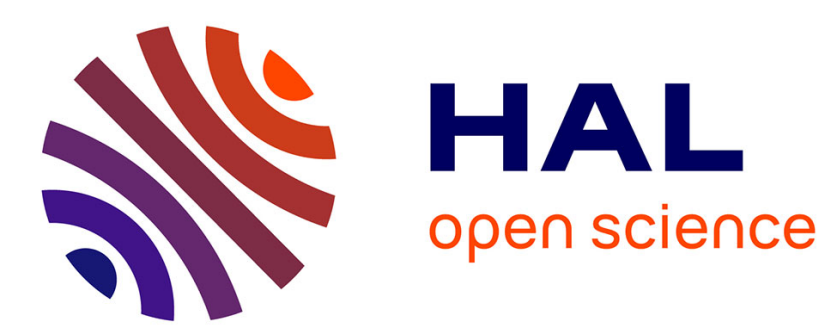

\title{
Characterisation of oxidised aluminium powder: Validation of a new anodic oxidation bench
}

Nicolas Gascoin, Philippe Gillard, Guillaume Baudry

\section{To cite this version:}

Nicolas Gascoin, Philippe Gillard, Guillaume Baudry. Characterisation of oxidised aluminium powder: Validation of a new anodic oxidation bench. Journal of Hazardous Materials, 2009, 171 (1-3), pp.348357. 10.1016/j.jhazmat.2009.06.010 . hal-00641607

\section{HAL Id: hal-00641607 https://hal.science/hal-00641607}

Submitted on 16 Nov 2011

HAL is a multi-disciplinary open access archive for the deposit and dissemination of scientific research documents, whether they are published or not. The documents may come from teaching and research institutions in France or abroad, or from public or private research centers.
L'archive ouverte pluridisciplinaire HAL, est destinée au dépôt et à la diffusion de documents scientifiques de niveau recherche, publiés ou non, émanant des établissements d'enseignement et de recherche français ou étrangers, des laboratoires publics ou privés. 
Characterisation of Oxidised Aluminium Powder: Validation of a new Anodic Oxidation Bench Nicolas Gascoin*, Philippe Gillard, Guillaume Baudry

PRISME Institute, Orleans University, 63 avenue de Lattre de Tassigny, 18020 Bourges, France

\section{Abstract}

Aluminium powder is of major interest in many applications but it presents a risk due to its high explosibility, particularly when dispersed in air. The safety is directly linked to the particles oxidation because the Minimum Ignition Energy (MIE), which is required to initiate an Al dust explosion, increases with the oxide layer thickness. This study provides a controlled method to furnish reproducible homogeneous set of powder for such safety studies. Thanks to a new experimental bench, the influence on the oxidation rate of seven treatment parameters is investigated (current density, time of treatment, acid concentration, mass of powder, particles size, stirring, neutralisation by ammonia solution). The oxide content is plotted versus the current density, the time and the acid concentration to provide reference curves for further elaboration of oxidised powder. The particles size of sieved powder is measured before and after treatment by different methods (optical and Scanning Electron Microscopes, laser measurement). A high refinement of the powder in terms of size distribution is achieved thanks to the employed sieving. The present bench and the elaborated procedure are of great interest to provide well calibrated oxidised powder directly available for safety studies. The time must be adjusted, depending on the wanted oxide content -from 2 wt.\% to 18 wt.\%-, and the other treatment parameters must be kept constant: acid concentration $(5 \mathrm{wt} . \%)$, current density $\left(1 \mathrm{~A} \cdot \mathrm{dm}^{-2}\right)$, treated powder $(20 \mathrm{~g})$. In these conditions, the ratio of the oxide layer thickness on the particles diameter is found to be constant for a given oxide content whatever the particles size.

\footnotetext{
* Corresponding Author. Tel: 0033-2-48-23-84-73; fax: 0033-2-48-23-84-71, E-mail adress: Nicolas.Gascoin@univorleans.fr (N. Gascoin)
} 
Keywords: Aluminium Micrometric Powder; Anodic Oxidation; Hazard Mitigation; Explosion Safety; Design of Experiments.

\section{Introduction}

The aluminium powder, from millimetric flakes to nanoparticles, is often used in various applications. A direct link exists between its initial oxidation state and its combustion properties; such as the Minimum Ignition Energy (MIE) and the flame velocity. The nanoscale is often related to propulsion applications [1] and pyrotechnic compounds because of the high burning rate of such small particles due to their high specific contact surface [2],[3]. The nanometric powder also presents the advantage to reduce the waste after combustion [4]. Thus, it is replacing the micrometric one though this latest is still considered and characterised, mainly in terms of combustion [5]. But the micrometer particles are still found for applications like organic coating [8] even if the actual trend is to use smaller ones [6]. The microparticles represent about two orders more than the nano ones on the world market [9]. This justifies considering them; three others reasons are given below.

The oxide layer covering the particles is often undesirable because it causes them to be less reactive [10]. But it could be a source of safety. Geisler [11] gives the example of a motor which exploded due to violent combustion instabilities. This was attributed to the new aluminium particles, less oxidised, which were used. This is a first example for which it could be interesting to use aluminium particles with controlled oxide layer. This means of safety is notably studied for nanoparticles [12].

Another example using controlled oxide layer is linked to the physical and optical properties of the alumina which modify, through the light refraction, the perception of colours and shine of organic coating and paint [13]. It is possible to adjust the oxide layer thickness of aluminium particles used in painting to vary this esthetical effect. 
Thirdly, alumina particles are also used in copper matrix that is intended to serve at high temperature [14],[15]. The addition of $\mathrm{Al}$ or $\mathrm{Al}_{2} \mathrm{O}_{3}$ is investigated with nano- and microsized particles. For the authors, the addition of $\mathrm{Al}$ particles in copper matrix, then oxidised $20 \mathrm{~h}$ in air at elevated temperature, increases the microhardness. It appears to be the best combination of the thermal stability and electrical conductivity. Thus, providing a way to oxidise Al particles in few minutes could be interesting at larger $\mathrm{Cu}$ matrix production scale.

Finally, regarding numerous safety studies on Aluminium particles (linked to the ATEX rule), the oxide layer thickness plays an important role on ignition [16]. Augmenting this thickness, thus the oxide content (Figure 1), increases the $\mathrm{E}_{50}$ energy (50\% of ignition probability as defined in [16]). No alumina is found in the core of the particles. This has been shown in previous work [16] thanks to EDS analysis (Energy Dispersive X-ray Spectroscopy). The respective O and Al atomic percents are plotted along the particle diameter. The $\mathrm{O}$ atoms appear only near the surface. The ratio of $\mathrm{Al}$ and $\mathrm{O}$ atoms corresponds to the alumina formula $\left(\mathrm{Al}_{2} \mathrm{O}_{3}\right)$ on the surface [16]. In the present study (like in [16]), the term "oxide content" refers to the oxide quantity that is found on the particles surface. The initial Al particles present a natural oxide layer of few nanometres, which is equivalent to an oxide content of about $0.5 \%$. The oxide layer thickness can be increased artificially by anodic oxidation for example. This is a very well-known technique [8] for Al pieces of various shapes but it is rarely applied to powder because of the difficulty to provide a suitable electrical contact between the anode and the powder. It is thus necessary to supply a way of oxidising such $\mathrm{Al}$ micrometer particles by controlling the experimental treatment parameters in order to obtain the wanted oxide content on a given commercial powder. This is required in order to conduct experiments on Al safety in good conditions.

Fig. 1 shall be placed here.

The previous work conducted by Baudry et al. [16],[17] used an installation of surface treatment to oxidise the powder. In this further step, it is chosen to investigate in details the way to obtain suitable oxidised Al powder. A new dedicated anodic oxidation installation is presented for 
powder with a set of pre- and post- experimental procedures (sieving, particles size measurement, oxidation treatment, filtering). In this paper, the oxidation does not mean the combustion of the powder but only the particle surface conversion into alumina thanks to an electrochemical process in a sulphuric acid solution. The direct current form is used for the present work.

Some studies can be found in the literature on anodic oxidation of powder but always on compacted powder forming solid electrodes or pressed pellets [7]. This is not an appropriate method to obtain non agglomerated powder for safety studies. The oxidation of non agglomerated powder is found in the literature by means of fluidised bed in air for nanoparticles. To our knowledge, there is only one paper available in the open literature dealing with the anodic oxidation of Al micrometric powder [8]. The authors use two kinds of anode. The first one is a horizontal one in titanium on which the powder is laying; the second one is made of compacted Al powder linked by a water-soluble ligand, which is dissolved in the electrolyte during the process. The Al electrode shows the highest oxide content because of a better electrical contact. Nevertheless, a problem of oxidised Al powder homogeneity appears. It could be due to the repartition of electrical current lines and to the lack of stirring. The determination of oxide content is made by selective chemical dissolution. They observe that the oxide content reaches a limiting maximum value after five minutes for all the intensity value (from 6 A to 10 A with very small electrodes surfaces, that is to say several hundreds of A.dm ${ }^{-2}$ ).

Fundamentally, the anodic oxidation of solid aluminium parts is well-known. The oxide forming and growing are controlled mainly by ionic conduction owing to the electrostatic field produced in the oxide by the applied current [19],[20]. The different interfaces (metal-oxidesolution) play a role in transfer processes. But no extension of these results is found for the powder oxidation in acid solution. Furthermore, it does not inform quantitatively on which treatment parameters should be used to obtain a given oxide content. The understanding of oxide growing on Al powder is a very complex phenomenon that is not investigated in this paper. 
In the present study, we aim at establishing a detailed procedure to treat $\mathrm{Al}$ powder and to give reference treatment parameters to use in order to obtain the wanted oxide content. The improvements of the bench, compared with the previous one, are described and explained, such as the steps of the suggested experimental procedure. A design of experiments [21] has been used to estimate the influence of treatment parameters. This study is performed in the framework of Al powder safety. There is a direct link between the feasibility of the process and the determination of Minimum Ignition Energy of Al cloud in the laboratory.

\section{Experimental}

Baudry et al. [16],[17] used a pedagogic installation of surface treatment to oxidise the powder. After characterisation by means of Thermogravimetry Analysis (TGA) and Scanning Electron Microscope (SEM), the powder was placed in a Hartmann apparatus [18] to test its explosibility [16]. The Hartmann tube applies compressed air at the bottom of apparatus to form dust cloud and to initiate it by an electrical spark (Figure 2). In view of the difficulty to control the powder oxidation, Baudry et al. were not able to test samples with oxide content between $4 \mathrm{wt} \%$ to $6 \mathrm{wt} . \%$ and between $7 \mathrm{wt} . \%$ to $9 \mathrm{wt} . \%$. The authors estimated the uncertainties on the oxide content to be lower than \pm 0.573 wt.\% for the initial unsieved powder [17]. This is reported on the figure 1 . The variation of the amount of oxide content was obtained by only adjusting the time; all other treatment parameters were uncontrolled.

\section{Fig. 2 shall be placed here.}

We now intend in this study to investigate the influence of other treatment parameters. For this purpose, the sieving of powder allows obtaining the sets of $\mathrm{Al}$ powder with given size distribution. The samples are oxidised with fixed treatment parameters in the dedicated bench (Figure 3). This latest is composed of a cylindrical glass tank of 2.5 litres with concentric cylindrical $\mathrm{Pb}$ cathode and $\mathrm{Ti}$ anode. It is filled with sulphuric acid solution. An air or magnetic 
agitation is possible. The $\mathrm{Al}$ powder is enclosed in a porous bag to avoid its dispersion in the bath. The powder is then dried before measurements are done. This brief description is detailed in the following sections.

\section{Fig. 3 shall be placed here.}

\subsection{Sieving procedure of Al powder}

The Al powder, which is used by Baudry et al. for the safety studies is a commercial micron sized aluminium powder (purity $>99.7 \%$ ) supplied by the company "Métaux \& Chimie" and referenced F3915 [16]. Its distribution presents a maximum fraction (5 vol.\%) around $35 \mu \mathrm{m}$ but also a peak near $7 \mu \mathrm{m}$ (4 vol.\%) [16]. An efficient way of sieving is required to provide homogeneous set of powder before testing the influence of the particles size on the oxidation. The homogeneity of $\mathrm{Al}$ powder set may also be correlated to the one of the treatment. Furthermore, the MIE determination may depend on the ratio of the oxide layer thickness on the Al particle diameter.

A new sieving method has been proposed to avoid the agglomeration of particles by electrostatic charging and to force the big particles through small sieves. Four sieves $(20 \mu \mathrm{m}$, $30 \mu \mathrm{m}, 40 \mu \mathrm{m}, 50 \mu \mathrm{m}$ ) are assembled together and fixed on the vibrating table (4s of moderate intensity vibrations by interval of $1 \mathrm{~s}$ ). The powder is deposited in the biggest sieve and ethanol is poured on it to separate particles naturally ( $50 \mathrm{ml}$ every 8 to 12 minutes). This allows sieving in less than an hour about 4 grams of powder (required quantity for a statistical test of explosibility [17]).

\subsection{Particles size characterisation and distribution}

Three techniques are used to evaluate the distribution of particles depending on their size. The laser one is considered to be reliable but a former highly frequent bimodal distribution of $\mathrm{Al}$ particles [16] incites us to test other methods. The distribution of the particles, depending on their size, is expressed by the number of particles or by their volume, assuming they are spherical. 


\subsubsection{Laser measurement}

A laser diffraction technique (Malvern, Spraytec) is combined with a specific apparatus used to put in suspension the $\mathrm{Al}$ powder by air injection [17]. It has been shown that such measurement is reproducible. The main drawback is due to a possible agglomeration of particles.

\subsubsection{Optical microscope}

The optical microscope (Bausch \& Lomb, MicroZoom), equipped with a video camera, is used with a statistical method to observe the Al powder. An adapted empirical procedure has been established after several trials to get reliable powder measurements. Fifty measures are realised and are available to estimate the distribution of particles size of a given sample of sieved powder.

\subsubsection{Scanning Electron Microscope}

The SEM (LEO, 1455 VP - Partial Vacuum) is used to observe the oxide layer thickness and to evaluate the diameter of $\mathrm{Al}$ particles. This gives the ratio of the oxide layer thickness on the particles diameter. By assuming the oxide is uniform around spherical Al particles, it is possible to compute the oxide content of the overall powder for comparison with TGA results. The preparation of samples is described in Ref. [17].

\subsection{Surface treatment of $\mathrm{Al}$ powder}

Formerly, the way to treat the Al powder for safety studies on aluminium particles [16] was to use an existing anodic oxidation bath of $50 \mathrm{~L}$ with six rectangular $\mathrm{Pb}$ cathodes $(400 \mathrm{~mm} \times 100$ $\mathrm{mm} \times 10 \mathrm{~mm}$ ). The anode was composed of an aluminium honey spoon (thirteen Al disks with a central rod), filed with $\mathrm{Al}$ powder and closed in a textile bag. The sulphuric acid concentration was not verified (probably around $20 \mathrm{wt} . \%$ ) and a constant voltage of $10 \mathrm{~V}$ to $15 \mathrm{~V}$ was applied (current

density of about $2 \mathrm{~A} \cdot \mathrm{dm}^{-2}$ ). The bench presented several drawbacks that are now corrected by the new apparatus. 
A stirring in a smaller tank is used to avoid the particles agglomeration. The oxidation of the anode and the agglomeration of particles on it are solved by using a titanium electrode, whose standard electrical potential $\left(-1.75 \mathrm{~V}\right.$ at $298 \mathrm{~K}$ for $\left.\mathrm{Ti}^{2+}\right)$ is lower than that of aluminium $\left(\mathrm{Al}^{3+}:-1.67\right.$ V). Other tests have been done with Zinc anode (potential higher than aluminium: $-0.76 \mathrm{~V}$ ) and did not gave much different results. The titanium anode and the $\mathrm{Pb}$ cathode are now cylindrical (respectively $40 \mathrm{~mm}$ and $190 \mathrm{~mm}$ of diameter) in order to homogenise the repartition of the electrical current lines. The current density used in the paper is calculated by considering the anode surface and not the metallic powder one, which is obviously difficult to express.

To slow down the oxidation process, the sulphuric acid concentration in the bath is decreased even to $5 \mathrm{wt} . \%$ and the current density even to $0.5{\mathrm{~A} . \mathrm{dm}^{-2}}^{2}$. A high current density oxidises the powder in few minutes (about $12 \%$ after $5 \min$ [17]), which is difficult to control. The quantity of $\mathrm{Al}$ powder introduced in the bath varies from $5 \mathrm{~g}$ to $10 \mathrm{~g}$ because it is retained as a treatment parameter for this study. To have stable operating conditions, the intensity is kept constant by increasing the voltage to compensate the electrical resistance, which rises. Indeed, the electrical resistance of alumina is higher than the one of aluminium.

Even if the alumina does not significantly dissolve at room temperature without intensity; that may locally appear if the bath is not sufficiently stirred and if warm zones appear (over $300 \mathrm{~K}$ ). A way to avoid alumina dissolution is to plunge the powder directly in ammonia solution after treatment in order to neutralise the sulphuric acid effect. That would allow observing the oxide surface with or without the neutralisation. The reproducibility issues encountered by Baudry et al. during ignition tests [17] may also be linked to the open porosity of the oxide layer and that may be tested by sealing alumina with hot water $\left(95^{\circ} \mathrm{C}\right)$.

Several parameters are monitored during the experiments to observe their variations and to evaluate their impact on the process (temperature, $\mathrm{pH}$, electrical conductivity, electrical current and voltage). The voltage is regularly increased during the experiment in order to compensate the intensity decrease due to the electrical resistance of alumina. 


\subsection{Thermogravimetry Analysis}

The thermogravimetry analysis is commonly used to estimate the oxide content of aluminium powder [22], [23]. A very good study on the alumina formation on Al particles is given by Trunov et al. [24]. Thanks to the TG apparatus (SETARAM, SETSYS 16/18 TG), the Al powder (sample of about $13 \mathrm{mg}$ ) is oxidised under air atmosphere. The mass of the sample increases by addition of oxygen, conducting to the transformation of $\mathrm{Al}$ into $\mathrm{Al}_{2} \mathrm{O}_{3}$. If the mass increase of the powder in the TG balance is lower than the theoretical maximum value for pure Al, it is due to the presence of alumina in the initial powder sample. The same parameters for the TGA as [16] are used (thermal increase at a rate of $20 \mathrm{~K} \cdot \mathrm{min}^{-1}$ from $295 \mathrm{~K}$ to $1863 \mathrm{~K}$, then isotherm of $3 \mathrm{~h}$ ). The determination of oxide content (detailed in [16]) is based on the comparison to a total oxidation of Al into $\mathrm{Al}_{2} \mathrm{O}_{3}$ by $\mathrm{O}_{2}$, which conducts to a mass increase of $89 \%$. This oxide content is the parameter used in all this paper to judge the oxidation of the powder. The coating ratio (mass ratio of oxide on $\mathrm{Al}$ ) is equal to the unity plus the oxide content.

\subsection{Parameters of treatment and design of experiment}

The design of experiment has been used in order to propose a limited number of tests suitable to evaluate the implication of seven treatment parameters on the oxide content. These seven parameters and their two levels are given in Table 1 . The low level is referred as - and the higher one as + . This will be important to compute the effect of each parameter on the results of oxide content. The treatment parameters are considered to be independent to use an Hadamard matrix of eight tests. This highly limits the number of experiments but it does not allow evaluating the possible interactions of treatment parameters. The result under study for the design of experiment is the final oxide content of treated Al powder.

The influence of the three main parameters has been further studied to provide suitable reference curves for future oxidation treatment. Some results on successive sieving will be given in 
the next section. After treatment, the oxidised Al powder is immersed in ammonia solution or deionised water to evacuate the sulphuric acid before rinsing and filtering in paper. The powder is then dried two days in air atmosphere at $353 \mathrm{~K}$. The titanium electrode is cleaned by corundum projection to evacuate any kind of oxide and then rinsed in ethanol with ultrasonic.

Tab. 1 shall be placed here.

\section{Results and Discussion}

The particles size is of great interest because the present study must determine if the oxidation activity of powder depends on this parameter. It also allows computing the ratio of the oxide thickness on the particles diameter for different oxide content and different size of particles. This could be a key point in the safety studies to understand the explosibility tests.

\subsection{Particles size distribution}

After counting the number of particles corresponding to several size ranges, it is possible to plot the resulting powder distribution. That can be done for the initial unsieved powder but also for each sieving range corresponding to the size of the sieves. By assuming the particles are spherical, the number of particles of a given diameter can be interpreted by its volume (in $\mathrm{m}^{3}$ ). The distribution of particles can thus be given in terms of number of particles or in terms of their volume. We will see that this is far to be similar.

\subsubsection{In terms of number}

The sieved $\mathrm{Al}$ powder is observed by optical microscope and by laser technique (Figure 4). The results are expressed, for a given particles diameter range, in percent of the particles number of this range related to the overall particles number. The powder obtained with the sieve of $50 \mu \mathrm{m}$ size is not considered because its explosion risk is too low [16]. The optical method enables to detect 
and to measure very fine particles (smaller than $5 \mu \mathrm{m}$ ) while the laser one does not because of a lack of accuracy and because of an agglomeration of these particles. But with 50 measures, the visualisation presents the limitation of the counting with statistical errors for the biggest particles. This is not the case with the laser because it performs several hundreds to thousands of measures. Nevertheless the laser results on biggest particles can be questionable as they can be due to agglomeration of small particles.

Fig. 4 shall be placed here.

The optical measurements, qualitatively better, reproduce the particles size increase from Figure $4 \mathrm{a}$ to Figure $4 \mathrm{~d}$ compared to the laser technique. Indeed, no particles over $10 \mu \mathrm{m}$ are detected in the Figure 4a (for powder sieved under $20 \mu \mathrm{m}$ ) while about $10 \%$ are detected in the Figure $4 \mathrm{~d}$ (powder in the range 40-50 $\mu \mathrm{m}$ ). The maximum peak of small particles in the range 5$10 \mu \mathrm{m}$ decreases continuously from $78 \%$ (Figure $4 \mathrm{a}$ ) to $52 \%$ (Figure 4d). Nevertheless, these results, which are related to the number of particles counted for each size, do not correspond to the sieves sizes.

The necessity of sieving is clear. One can observe that for a given range of sieving, for example 20-30 $\mu \mathrm{m}$ (Figure 4b), no particle is found in this range with both optical and laser methods. All the particles present smaller diameters. This is also due to the fact that very small particles (less than $10 \mu \mathrm{m}$ ) are much more numerous than others. Consequently, the sieving does not allow refining a powder if the distribution in term of particles number is of interest. But thanks to this work, it is possible to estimate the uncertainties on the particles diameter.

\subsubsection{In terms of volume}

As the high number of small particles perturbs the counting, the size distribution is studied in terms of volume (Figure 5). The small particles, even numerous, represent a small volume compared to the one of big particles. The particles which are smaller than $10 \mu \mathrm{m}$ are still widely present but they are now in minority. Furthermore, the relative importance of the fine particles peak 
decreases while the sieve size increases, which is satisfactory. The reference peak corresponds to the size of the sieve and it should be predominant. Nevertheless it is the case only for the biggest sieve, and not for the others. This peak is centred on the particle diameter of $22 \mu \mathrm{m}$ for the powder sieved under $20 \mu \mathrm{m}$ (Figure 5a), $24 \mu \mathrm{m}$ for the range $20-30 \mu \mathrm{m}$ (Figure 5b), $27 \mu \mathrm{m}$ for the range 30$40 \mu \mathrm{m}$ (Figure 5c) and $46 \mu \mathrm{m}$ for the range 40-50 $\mu \mathrm{m}$ (Figure 5d). These results are judged acceptable but the successive sieving can bring a better separation to provide a volume majority for the reference peak.

\section{Fig. 5 shall be placed here.}

\subsection{Successive sieving}

To refine the particles size distribution of initial Al powder, several successive sievings have been realised to "purify" the samples. An example is shown for the powder sieved in the range 30$40 \mu \mathrm{m}$ (Figure 6). The magnitude ratio of small particles peak on the reference peak decreases drastically from 9.3/7.2=1.29 (Figure 6a), to 7.2/7.9=0.91 (Figure 6b), to 6.3/9.1=0.69 (Figure 6c). A sieved powder largely representative of the sieving range is obtained, here $30-40 \mu \mathrm{m}$. The maximum of the reference peak, initially found around $27 \mu \mathrm{m}$, passes to $32 \mu \mathrm{m}$ then $30 \mu \mathrm{m}$ after the second and third sieving.

\section{Fig. 6 shall be placed here.}

During these successive sievings, the initial powder mass obtained in the range $30-40 \mu \mathrm{m}$ has been divided by a factor 5 . From the original $32.9 \mathrm{~g}$ of $30-40 \mu \mathrm{m}$ powder, $17.8 \mathrm{~g}$ were collected after the second sieving in the same range while $6.7 \mathrm{~g}$ show a particle diameter lower than $30 \mu \mathrm{m}$ and $6.6 \mathrm{~g}$ a diameter higher than $40 \mu \mathrm{m}$. According to the mass balance, $1.8 \mathrm{~g}$ are found to be lost in the overall sieving and filtering process, that is to say $5 \%$ of the initial powder mass. Then after the third sieving, $6.2 \mathrm{~g}$ are in the range of study.

\subsection{First results of design of experiments}


The measurements made during the anodic oxidation show almost constant values. The temperature remains between $291 \mathrm{~K}$ and $298 \mathrm{~K}$, depending on the room temperature. It slightly increases during the process (not more than $2 \mathrm{~K}$ ). The $\mathrm{pH}$ is near 1.5 and the electrical conductivity is also stable but it depends on the experimental test conditions because it is related to the sulphuric acid concentration (from $150 \mathrm{mS}$ to $600 \mathrm{mS}$ ). The intensity is kept constant during the treatment to fit the desired current density (computed based on the anode surface) and the resulting voltage changes from $10 \mathrm{~V}$ to $25 \mathrm{~V}$ depending on the test and the oxidation of powder. The quantity of powder, which is obtained after the treatment, the rinsing, the filtering and the drying of Al powder, has been increased through the successive experiments. From an initial mass of $5 \mathrm{~g}, 4.8 \mathrm{~g}$ are finally gathered (4\% of loss in the successive steps).

The results of the design of experiment are summarized in Table 2. The Hadamard matrix is constituted of seven columns and eight lines, corresponding respectively to the seven treatment parameters to be tested and to the eight experiments recommended by Hadamard. The seven parameters are considered with their low level noted "-" and their high level noted "+" (with the values given by the table 1). The oxide content (unit: vol.\%) which results from each of the eight tests is measured by TGA and it is noted by $Y_{i},(i=1 . .8)$. The influence (noted $b_{i}, i=1 . .7$ ) of each parameter is computed by adding all the results $\mathrm{Y}_{\mathrm{i}}$. Each of them is multiplied by the related level of the considered parameter (low or high), that is to say -1 or +1 . The term $b_{0}$ is the sum of all the effects $b_{i}(i=1 . .7)$. The more the effects $b_{i}$ are far from 0 , the more they influence the oxide content. The particles size distribution has a limited impact on the oxidation process. This is understandable because the oxidation is mainly controlled by the electrical phenomena. But the size distribution can play a role on the oxide thickness on particle diameter ratio and this will be studied in the next section.

\section{Tab. 2 shall be placed here.}

Thanks to this design of experiment, it is firstly seen that the mass of powder which is treated does not influence notably the oxidation process. Considering the same treatment 
parameters, the more the powder, the less the oxide content. The current density should be increased with the powder mass to reach the same oxide content. These two parameters may not evolve proportionally. The stirring also does not impact on oxidation for the same reason. But these two last parameters can impact on the homogeneity of the oxidised powder sample and this cannot be observed by simply measuring the oxide content. The SEM visualisations or the ignition tests (safety study) could bring further information.

The current density and the sulphuric acid concentration appear to be the most important treatment parameters regarding their respective results $b_{2}=22.91$ and $b_{3}=23.16$. This is due to the fact that the process is electrochemical by nature. An interaction of these two parameters is possible but it cannot be taken into account in these first eight tests. Consequently, a more detailed study has been realised to identify the implication of both parameters in the oxidation of powder.

The neutralisation of oxidised powder by ammonia solution just after treatment is surprisingly the third most important parameter. Neutralising the powder helps keeping the oxide layer by avoiding its dissolution in the acid bath between the stop of intensity and the powder outlet of the bath. But this effect is questionable because it does not increase the oxide content of the powder. Thus, it is impossible to compare its effect to the intensity or the electrolyte electrical conductivity. In the design of experiment, there is a common "law" of $80 \%-20 \%$. That means that only $20 \%$ of the parameters are really influent on a process. Now three parameters out of seven correspond to $43 \%$. This shows that the effect of the third parameter, the ammonia solution one, is only due to an interaction of the two others.

The time of treatment is not shown to be very influent on the oxide content and this is probably the limitation of such a simple design of experiment matrix. The low level (10 min) may not be well chosen due to the rapidity of the oxidation. This point needs to be studied in details; that is why other specific tests have been realised to precisely investigate the effect of time.

\subsection{Influence of treatment parameters on anodic oxidation}


The oxide content (defined as the percentage of alumina found by TGA in the oxidised $\mathrm{Al}$ powder, see section 2.4.) of treated Al powder does not vary linearly with the sulphuric acid concentration (Figure 7). It is attributed to the non linear evolution of the electrolyte electrical conductivity, which presents a Gaussian trend centred on 25 wt.\% (roughly $150 \mathrm{mS}$ at 5 wt.\%, $600 \mathrm{mS}$ at $25 \mathrm{wt} . \%$ and $100 \mathrm{mS}$ at $80 \mathrm{wt} . \%$ ). The uncertainties on the acid concentration are judged to be negligible $(0.01 \%$ of accuracy). The rapid evolution of the oxide content in the range of $10 \mathrm{wt} . \%$ to $15 \mathrm{wt} . \%$ of acid in the bath highlights the fact that a low acid concentration should be used to precisely control the oxidation rate. This is confirmed by studying the influence of the time of treatment (Figure 8). Due to the high acid concentration (20 wt.\%), the oxide content is multiplied by a factor 5 in only 5 minutes (from 5 to 10 minutes of treatment). The rate of oxidation remains slightly constant from $10 \mathrm{~min}$ to $60 \mathrm{~min}$ of treatment $\left(0.1 \mu \mathrm{m} \cdot \mathrm{min}^{-1}\right)$. This is one order less than the one generally observed for the anodic oxidation of solid aluminium parts. The variations can be attributed to the average efficiency of the manual intensity adjustment. The uncertainties on the oxidation time are of the order of 2 seconds, that is to say lower than $0.67 \%$.

\section{Fig. 7 shall be placed here.}

\section{Fig. 8 shall be placed here.}

The current density, which is estimated with an accuracy of $6.7 \%$ (Figure 9), presents an optimum in terms of oxide content around $1.5 \mathrm{~A} \cdot \mathrm{dm}^{-2}$. For higher value of $2 \mathrm{~A} \cdot \mathrm{dm}^{-2}$, lower oxide content is observed. This is attributed to the "burning" phenomenon, which corresponds to a thermal increase near the anode. This is accompanied by a lower efficiency of the anodic oxidation.

\section{Fig. 9 shall be placed here.}

Finally, the oxide content is measured for the same experimental conditions as a function of the particles size distribution (Figure 10). Due to the uncertainty on the oxide content estimation (about $1 \%$ ), it is difficult to evaluate if the particles size distribution has an impact on the oxide content. It is assumed that this distribution does not impact on the oxidation. Thus, the three points on the figure 10 correspond to sample with identical oxide content. Consequently, it is interesting to 
observe the oxide layer thickness on these samples to estimate the ratio of oxide thickness on particles diameter. This point is further studied in the section 3.5.2.

Fig. 10 shall be placed here.

\subsection{Evaluation of the oxide layer thickness}

\subsubsection{Indirect measurement}

The maximum oxide content observed during the present experiments is about $18 \%$. It is obtained for powder in the range 30-40 $\mu \mathrm{m}$ with $1 \mathrm{~A} . \mathrm{dm}^{-2}$ and $20 \mathrm{wt} \%$ of sulphuric acid. Considering spherical particles with uniform oxide layer, this oxide content should correspond to a thickness of $2.1 \mu \mathrm{m}$ and $2.8 \mu \mathrm{m}$ for an Al particle diameter of $30 \mu \mathrm{m}$ and $40 \mu \mathrm{m}$ respectively. This should modify the particles size distribution. This one is thus measured by the laser techniques (whose resolution is finer than $1 \mu \mathrm{m}$ ) on two ranges of sieved powder; before and after the oxidation treatment (Figure 11). After treatment (Figure 11b), the 20-30 $\mu \mathrm{m}$ powder presents an inferior number of small particles (around $10 \mu \mathrm{m}$ ) than before (Figure 11a). This could indicate an agglomeration during the oxidation. The maximum of the reference peak is slightly shifted towards the biggest particle. Its maximum is found at $26 \mu \mathrm{m}$ while it was at $24 \mu \mathrm{m}$ initially (Figure 11a). If these $2 \mu \mathrm{m}$ are attributed to the oxide layer, the resulting oxide content can be computed to be $25.6 \%$. This is much more than the one measured by TGA $(10.1 \%)$. The qualitative trend of the particles size increase cannot be exploited quantitatively because of the low accuracy of the overall laser measurement method. Concerning the $30-40 \mu \mathrm{m}$ powder (Figure 11c), approximately the same amount of small particles around $10 \mu \mathrm{m}$ is found. The reference peak is also slightly shifted (Figure 11d) by $2 \mu \mathrm{m}$ (maximum found at $29 \mu \mathrm{m}$ in comparison with $27 \mu \mathrm{m}$ initially). The oxide content can then be computed $(23.8 \%)$ and compared to the measured one by TGA (10.9\%). Once again, a quantitative exploitation seems to be impossible.

Fig. 11 shall be placed here. 


\subsubsection{Direct measurement}

Three powder samples $(20-30 \mu \mathrm{m}, 30-40 \mu \mathrm{m}, 40-50 \mu \mathrm{m})$ are observed with the SEM (the same which were analysed with TGA to obtain the figure 10). The oxide layer thickness and the particle diameter are measured for several particles (one example is given by the figure 12). The ratio of these two parameters is calculated. The oxide content is evaluated by assuming spherical particles with uniform oxide layer (Table 3). A high difficulty to precisely evaluate the oxide layer thickness (up to $50 \%$ of uncertainty) is encountered as well as a dispersal of the particles diameter measures (up to $25 \%$ ) owing to a low distribution homogeneity. The measures on SEM visualisation present the same statistical drawback as the one previously described for the optical microscope. These too low accuracies are mainly due to the poor number of measures (only six), which are more difficult because of the SEM technique itself. The method employed to prepare the Al powder samples should also be revised, notably by using a more conductive resin, prepared at high temperature. Furthermore, by using an electrically charged resin, it may be possible to use an electro polishing instead of a mechanical one, which separates the Al particles from the surface.

\section{Fig. 12 shall be placed here.}

Thus, the quantitative exploitation of the data is hazardous (more than $100 \%$ of uncertainty of computed ratio and oxide content). But the main qualitative interesting point is the following. For a given oxide content, the ratio of oxide layer on particle diameter is the same for all the sieved powder. This can be easily confirmed by theoretical calculations of uniform layer around spherical particles. Consequently, the homogeneity of sample is shown to be of prior importance because if all the particles present the same oxide content, whatever their size, they will present the same oxide/diameter ratio, which is assumed to control the explosibility of powder [17]. The importance of sieving is again shown here.

\section{Tab. 3 shall be placed here.}

\section{Conclusions}


An experimental set-up has been proposed to oxidise a commercial aluminium powder with a reproducible and controllable method. It has presently no equal in open literature due notably to the difficulty of establishing an electrical contact between the powder and the electrodes. The initial Al powder has been sieved in three particles size ranges to study their oxidation $(20-30 \mu \mathrm{m}, 30-40$ $\mu \mathrm{m}, 40-50 \mu \mathrm{m})$. The successive sieving allows refining the powder by more than a factor two. The electrode material is the titanium, the geometry of both electrodes is cylindrical to have a better electrical current lines repartition, the stirring of the bath is proposed, a neutralisation by the ammonia solution is possible and other parameters than only the time of treatment have been investigated to vary and to control the oxide content of $\mathrm{Al}$ powder (current density, acid concentration, mass of treated powder, particles size distribution).

A design of experiment has been established and the major influence of some parameters has been shown: the time of treatment, the sulphuric acid concentration, the current density. A more detailed study of the relationship between these parameters and the oxide content has been conducted to establish three reference curves, which can now be used to estimate the oxide content for future treatment. Considering all the above work, the best parameters for the Al powder oxidation are: an acid concentration of $5 \mathrm{wt} . \%$, a current density of about $1 \mathrm{~A} . \mathrm{dm}^{-2}$, with a stirring, a neutralising by ammonia solution, an amount of powder of about $20 \mathrm{~g}$ for the described treatment apparatus. The quantity of $20 \mathrm{~g}$ is compatible with the amount required to conduct safety studies and to determine the Minimum Ignition Energy as a function of the oxide content. The time of treatment should be varied depending on the wanted oxide content. Due to the non linear effect of the treatment parameters on the oxidation, it is not possible to literally compute or predict the oxide content, based on the parameters level.

The particles size distribution has been measured before and after the treatment. The oxidation is shown to be qualitatively visible through this distribution. The oxide content has been computed thanks to TGA measures. It ranges from $2 \mathrm{wt} . \%$ to $18 \mathrm{wt} . \%$ depending on the treatment parameters. The SEM has also been used to estimate this information and to evaluate the oxide 
thickness, from to $174 \mathrm{~nm}$ to $682 \mathrm{~nm}$. This way of determination appears to be feasible even if the accuracy is much lower than that of TGA data. Nevertheless, the main advantage of SEM observations (beyond the fact that it shows the uniform oxide layer around each particle) is to evaluate the ratio of the oxide layer thickness on the particle diameter. This ratio appears to be slightly constant (for a given oxide content) whatever the initial particles diameter.

It has been mentioned that depending on the alumina thickness of $\mathrm{Al}$ particles, it could be possible to control the explosibility, and so the risk of this powder. The present bench (with the described optimised method for oxidising the $\mathrm{Al}$ powder) will be used in order to provide the required samples with oxide content that are missing to complete the figure 1. If a given level of safety is wanted for an industrial configuration, this figure can be used to estimate the required oxide content of the $\mathrm{Al}$ powder. Our research gives the relevant experimental parameters to reach the wanted oxide layer thickness in order to inhibit the Al powder explosion.

\section{Acknowledgements}

A. Butori is gratefully acknowledged for his remarkable experimental work. The authors would like to give sincere thanks to P. Bourreau for her help involving the English writing. The technical help of S. Bernard involving the SEM observations has been appreciated.

\section{References}

[1] Damian Tatum and Kenneth K. Kuo, "Physicochemical Considerations in Modeling Ignition

\& Combustion of Highly Non-Spherical Nano-Sized Aluminum Particles", 39th AIAA/ASME/SAE/ASEE Joint Propulsion Conference and Exhibit, 20-23 July 2003, Huntsville, Alabama

[2] S. F. Li, Z. K. Lin, T. F. Wang, Y. L. Sun, X. Han, S.Q.Yu, "The Effects of Aluminum Size on the Combustion Characteristics of High Energy Propellants with Higher Burning Rate", 42nd 
AIAA/ASME/SAE/ASEE Joint Propulsion Conference \& Exhibit, 9-12 July 2006, Sacramento, California.

[3] A. Shalom, H. Aped, M. Kivity, D. Horowitz, "The Effect of Nanosized Aluminum on Composite Propellant Properties", 41st AIAA/ASME/SAE/ASEE Joint Propulsion Conference \& Exhibit, 10 - 13 July 2005, Tucson, Arizona.

[4] Bill L. Miles and Jon L. Rackham, "The Effect of Aluminum Particle Size Distribution on TPH1148 Propellant Slag", AIAA-96-3271.

[5] Ying Huang, Grant A. Risha, Vigor Yang, and Richard A. Yetter, "Flame Propagation in Bimodal Nano/Micro-Sized Aluminum Particles/Air Mixtures", 44th AIAA Aerospace Sciences Meeting and Exhibit, 9-12 January 2006, Reno, Nevada.

[6] Mei-Rong Song, Li Song, Shu-Li Xu, Zhi-Jun Zhang, "Preparation of aluminum ultrafine particles by anodizing aluminium foil in acidic electrolyte containing chloride ions", Electrochimica Acta 53 (2008) 7198-7203, doi:10.1016/j.electacta.2008.05.006.

[7] W. J. Bernard and E. J. Fresia, "Anodic Oxidation of Porous Aluminium Pellets", Electrocomponent Science and Technology 1974, Vol. 1, pp. 59-64.

[8] L. Anicai, C. Trifu, L. Dima, "Anodic Oxidation and Coloring of Aluminum Powders", Metal Finishing, December 2000, 20-25.

[9] M. Kerans, "Development and applications of ultrafine aluminium powders", Materials Science and Engineering A 375-377 (2004) 120-126.

[10] Grant A. Risha, Eric Boyer, Robert B. Wehrman, and Kenneth K. Kuo, "Performance Comparison of HTPB-Based Solid Fuels Containing Nano-Sized Energetic Powder in a Cylindrical Hybrid Rocket Motor", 38th AIAA/ASME/SAE/ASEE Joint Propulsion Conference \& Exhibit, 7-10 July 2002, Indianapolis, Indiana.

[11] R.L. Geisler, "A Global View of the Use of Aluminum Fuel in Solid Rocket Motors", 38th AIAA/ASME/SAE/ASEE Joint Propulsion Conference \& Exhibit, 7-10 July 2002, Indianapolis, Indiana. 
[12] Young-Soon Kwon, Alexander A. Gromov, Julia I. Strokova, "Passivation of the surface of aluminum nanopowders by protective coatings of the different chemical origin", Applied Surface Science 253 (2007) 5558-5564.

[13] F. Jay, V. Gauthier-Brunet, F. Pailloux, J. Mimault, S. Bucher, S. Dubois, "Al-coated iron particles: Synthesis, characterization and improvement of oxidation resistance", Surface \& Coatings Technology 202 (2008) 4302-4306.

[14] Viseslava Rajkovic, Dusan Bozic, Milan T. Jovanovic, "Properties of copper matrix reinforced with nano- and micro-sized A12O3 particles", Journal of Alloys and Compounds 459 (2008) 177-184.

[15] Li Guobin, Sun jibing, Guo Quanmei, Wang Ru, "Fabrication of the nanometer Al2O3/Cu composite by internal oxidation", Journal of Materials Processing Technology 170 (2005) 336-340.

[16] G. Baudry, S. Bernard, P. Gillard, "Influence of the oxide content on the ignition energies of aluminium powders", Journal of Loss Prevention in the Process Industries 20 (2007) 330-336.

[17] G. Baudry, "Etude de l'inflammabilité d'un nuage de particules d'aluminium partiellement oxydées", Ph.D. Thesis, Orleans Univeristy, 07/05/2007.

[18] Dorsett, H. G., Jacobson, M., \& Nagy, J. (1960). Laboratory equipment and test procedures for evaluating explosibility of dusts. Report of Investigations 5424. US Bureau of Mines.

[19] G. Patermarakis, K. Moussoutzanis, Development and application of a holistic model for the steady state growth of porous anodic alumina films, Electrochimica Acta (2008), doi:10.1016/j.electacta.2008.11.064

[20] G. Patermarakis, "Transformation of the Overall Strict Kinetic Model Governing the Growth of Porous Anodic $\mathrm{A}_{2} \mathrm{O}_{3}$ Films on Aluminium to a Form Applicable to the Non-Stirred Bath Film Growth", Elecrrochimica Acta. Vol. 41. No. 16. pp. 260-2611. 1996.

[21] T. Hayakawa, S. Kageyama, M.L. Puri, "Special issue in Honour of Junjiro Ogawa (19152000): Design of experiments, multivariate analysis and statistical inferences", Journal of Statistical Planning and Inference, Volume 138, Issue 11, 1 November 2008, Page 3293. 
[22] C.E. Johnson, S. Fallis, A.P. Chafin, T.J. Groshens, K.T. Higa, I.M.K. Ismail, T.W. Hawkins, "Characterization of Nanometer- to Micron-Sized Aluminum Powders: Size Distribution from Thermogravimetric Analysis", Journal of Propulsion and Power, Vol. 23, No. 4, July-August 2007. [23] B. Rufino, F. Boulc'h, M.-V. Coulet, G. Lacroix, R. Denoyel, "Influence of particles size on thermal properties of aluminium powder", Acta Materialia 55 (2007) 2815-2827.

[24] M.A. Trunov, M. Schoenitz, X. Zhu, E.L. Dreizin, "Effect of polymorphic phase transformations in $\mathrm{Al}_{2} \mathrm{O}_{3}$ film on oxidation kinetics of aluminum powders", Combustion and Flame, 140 (2005) 310-318. 
Figure 1. Mitigation effect of the oxide content in the Al powder on the ignition energy [16].

Figure 2. Experimental bench with Hartmann tube used by Baudry et al. to test the explosibility of $\mathrm{Al}$ powder [16].

Figure 3. Particles size distribution (in number) of sieved Al powder with a theoretical diameter: a) lower than $20 \mu \mathrm{m}, \mathrm{b})$ in the range $20-30 \mu \mathrm{m}, \mathrm{c}$ ) in the range $30-40 \mu \mathrm{m}, \mathrm{d}$ ) in the range $40-50 \mu \mathrm{m}$.

Figure 4. Particles size distribution (in volume) of sieved powder with a theoretical diameter: a) lower than $20 \mu \mathrm{m}, \mathrm{b})$ in the range $20-30 \mu \mathrm{m}, \mathrm{c}$ ) in the range $30-40 \mu \mathrm{m}, \mathrm{d})$ in the range $40-50 \mu \mathrm{m}$.

Figure 5. Particles size distribution (in volume) of sieved powder in the range 30-40 $\mu \mathrm{m}$ after one sieving (a), two sieving (b) and three sieving (c).

Figure 6. Effect of the acid concentration on the oxide content.

Figure 7. Effect of the time of treatment on the oxide content.

Figure 8. Effect of the current density on the oxide content.

Figure 9. Oxide content of sieved powder treated with the same test parameters.

Figure 10. Particles size distribution before (a and c) and after (b and d) the oxidation treatment of sieved powder in the range $20-30 \mu \mathrm{m}$ ( $\mathrm{a}$ and b) and 30-40 $\mu \mathrm{m}$ (c and d).

Figure 11. SEM visualisation of Al micrometric particle with oxide layer.

Table 1. The seven selected parameters for the design of experiment with their two levels.

Table 2. Hadamard matrix of experimental tests with oxide content results and influence of parameters.

Table 3. Determination of the oxide content based on SEM observations. 


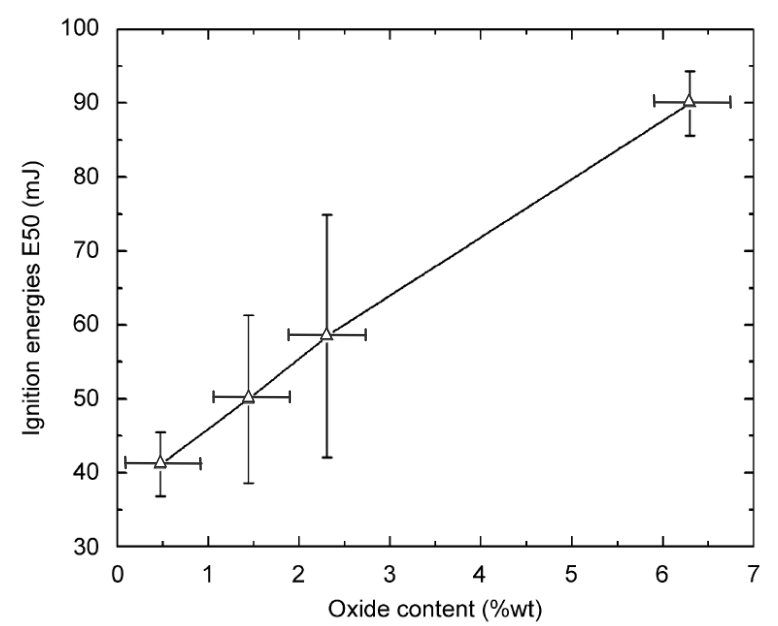

Figure 1. Mitigation effect of the oxide content in the Al powder on the ignition energy [16]. 


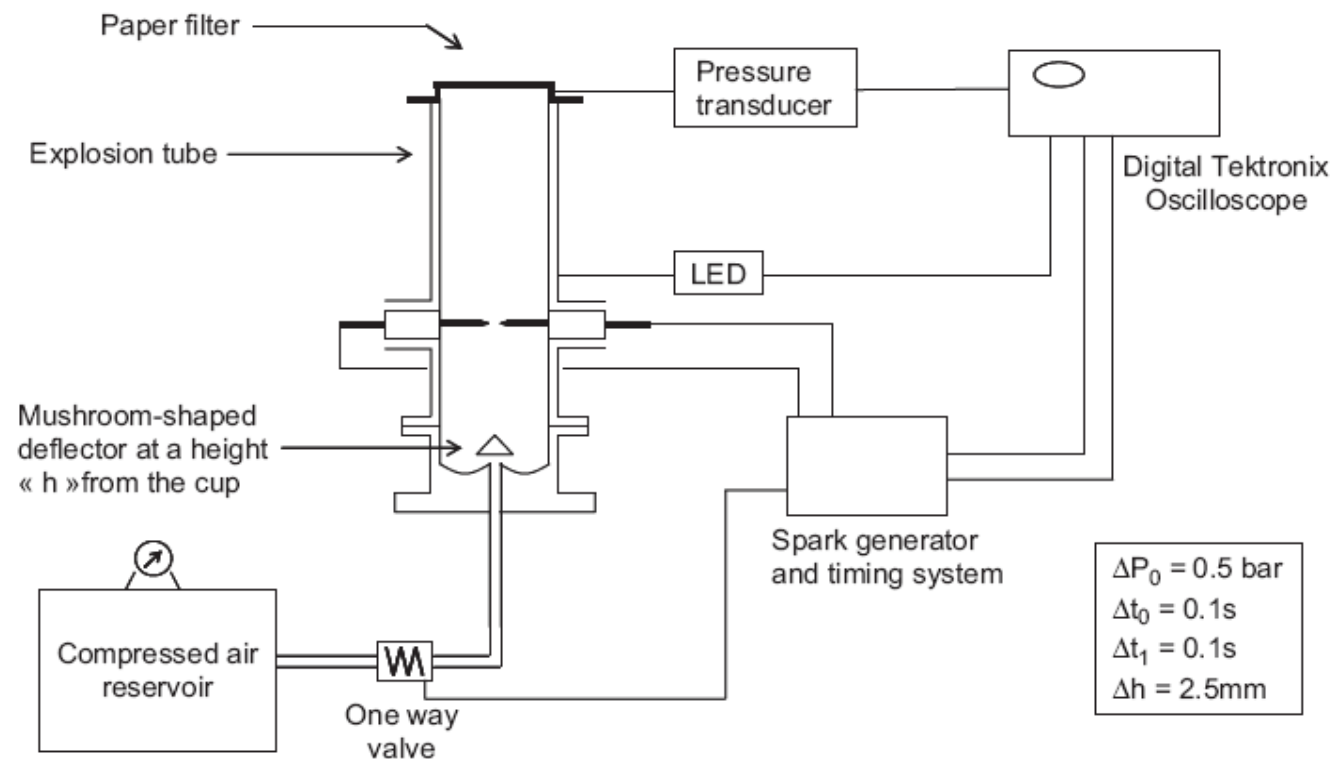

Figure 2. Experimental bench with Hartmann tube used by Baudry et al. to test the explosibility of Al powder [16]. 


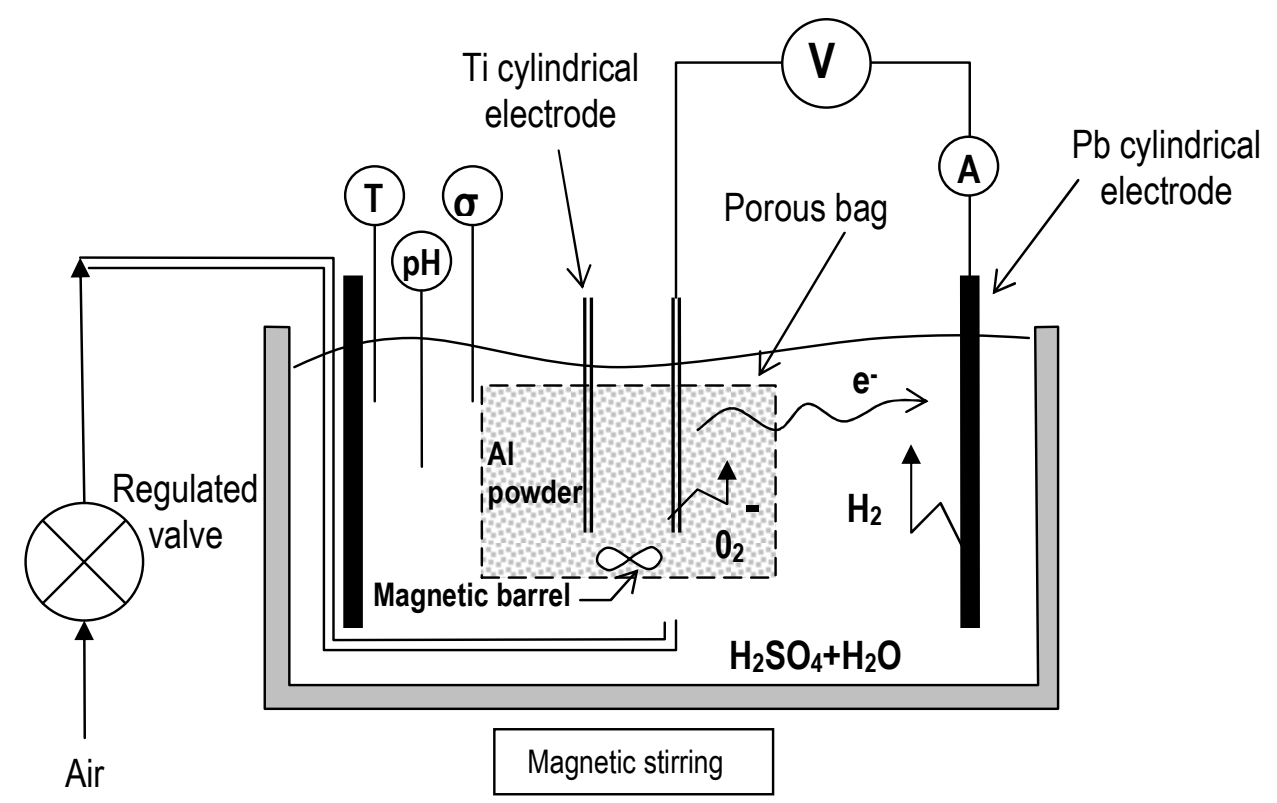

Figure 3. Anodic oxidation apparatus for $\mathrm{Al}$ powder treatment. 

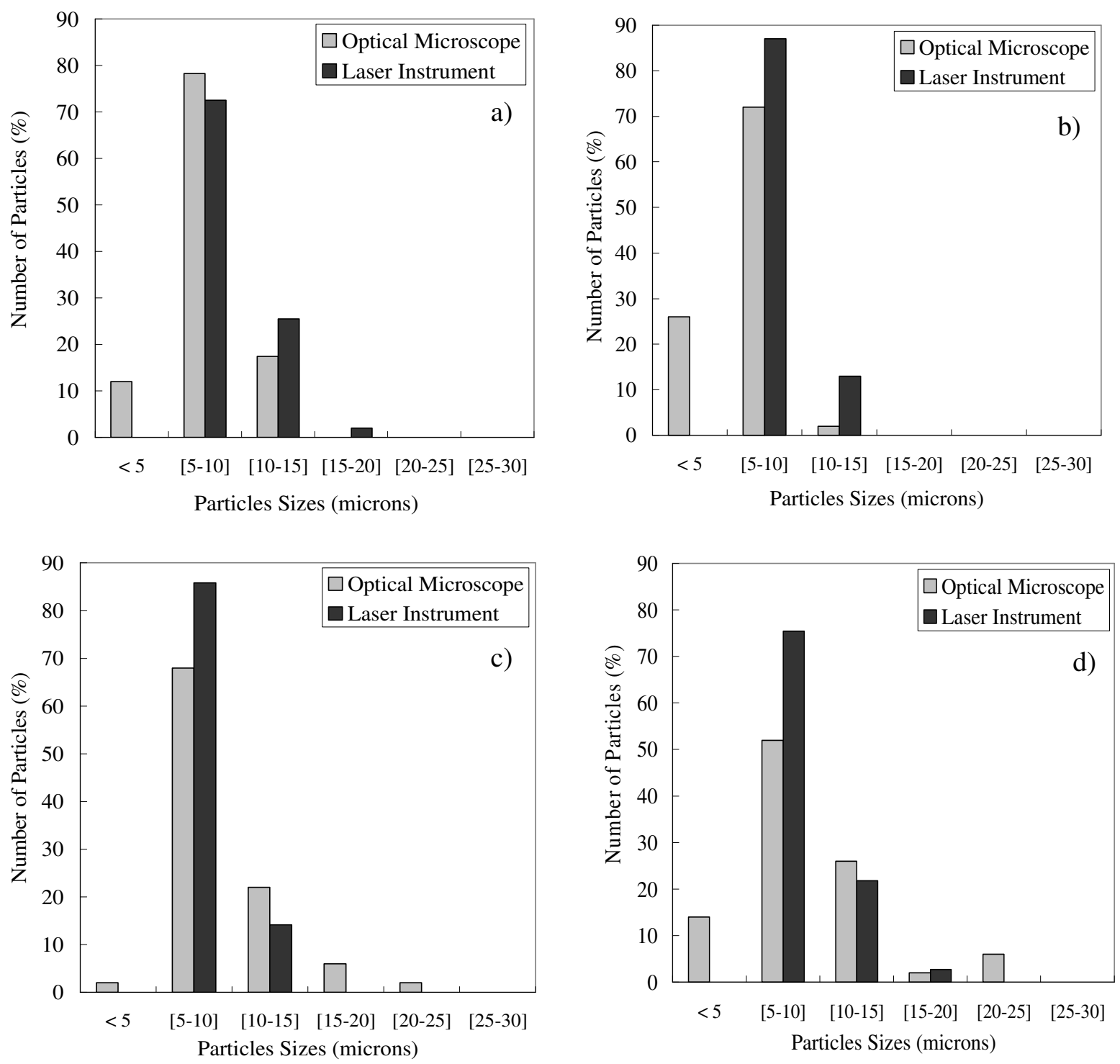

Figure 4. Particles size distribution (in number) of sieved Al powder with a theoretical diameter: a) lower than $20 \mu \mathrm{m}, \mathrm{b}$ ) in the range $20-30 \mu \mathrm{m}, \mathrm{c}$ ) in the range $30-40 \mu \mathrm{m}, \mathrm{d})$ in the range $40-50 \mu \mathrm{m}$. 

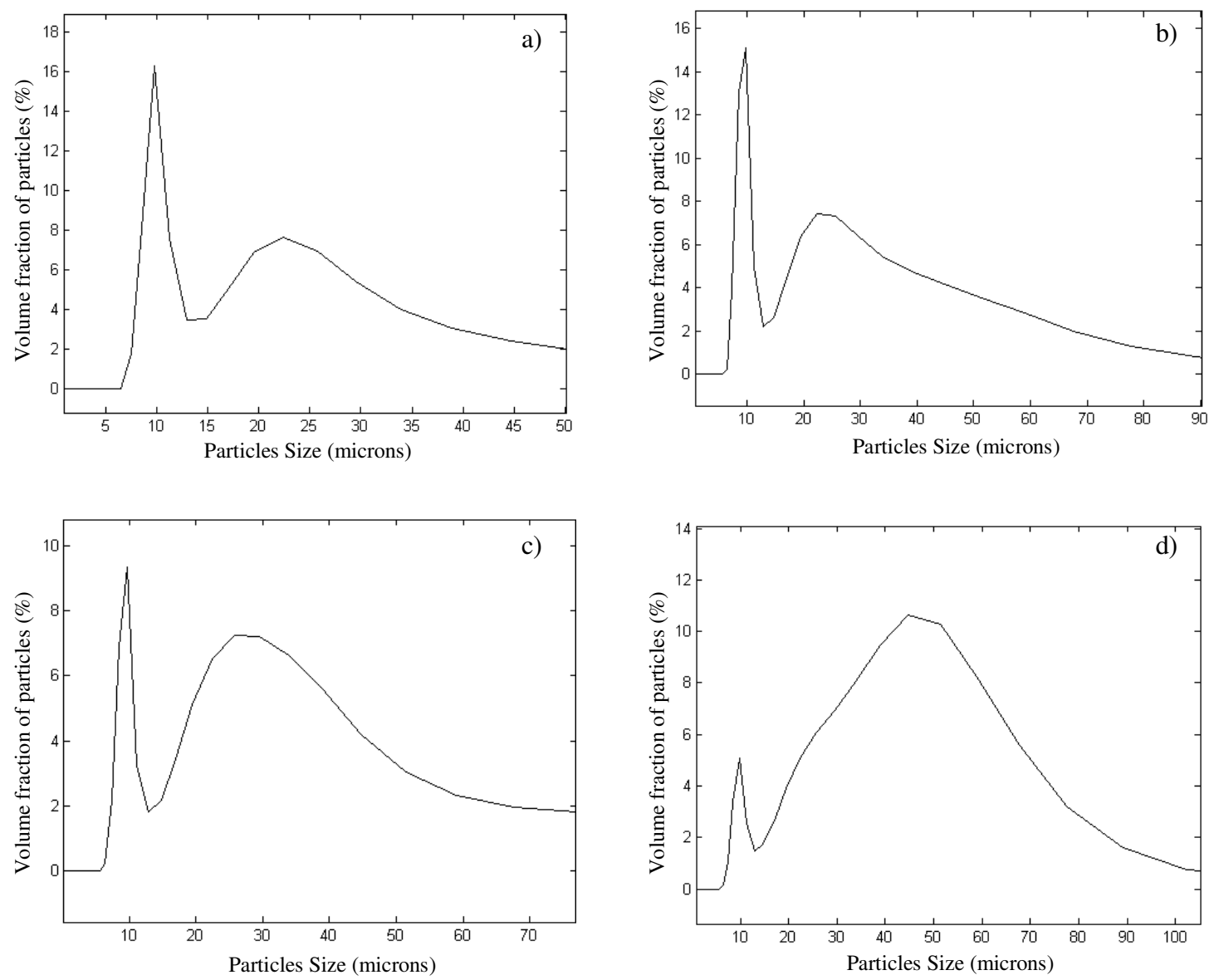

Figure 5. Particles size distribution (in volume) of sieved powder with a theoretical diameter: a) lower than $20 \mu \mathrm{m}, \mathrm{b}$ ) in the range $20-30 \mu \mathrm{m}, \mathrm{c})$ in the range $30-40 \mu \mathrm{m}, \mathrm{d})$ in the range $40-50 \mu \mathrm{m}$. 

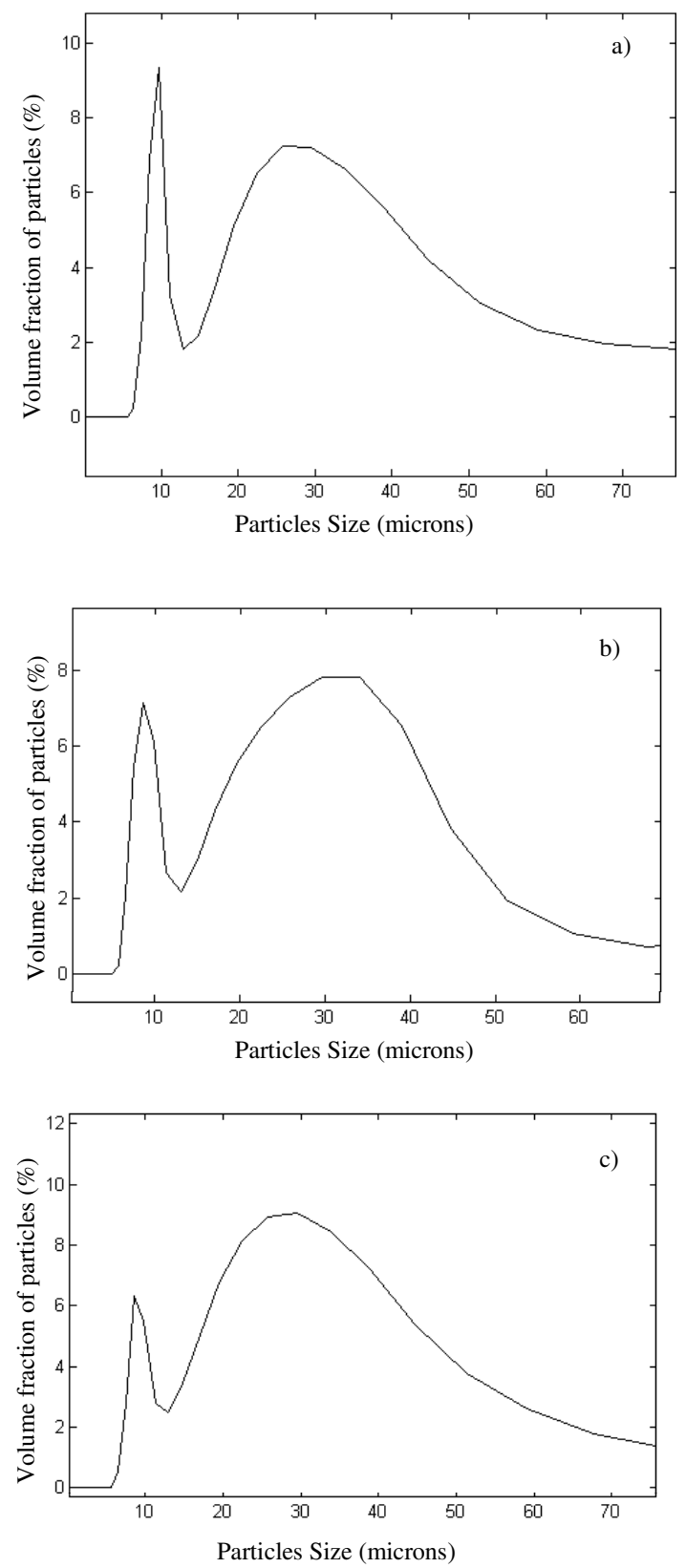

Figure 6. Particles size distribution (in volume) of sieved powder in the range $30-40 \mu \mathrm{m}$ after one sieving (a), two sieving (b) and three sieving (c). 


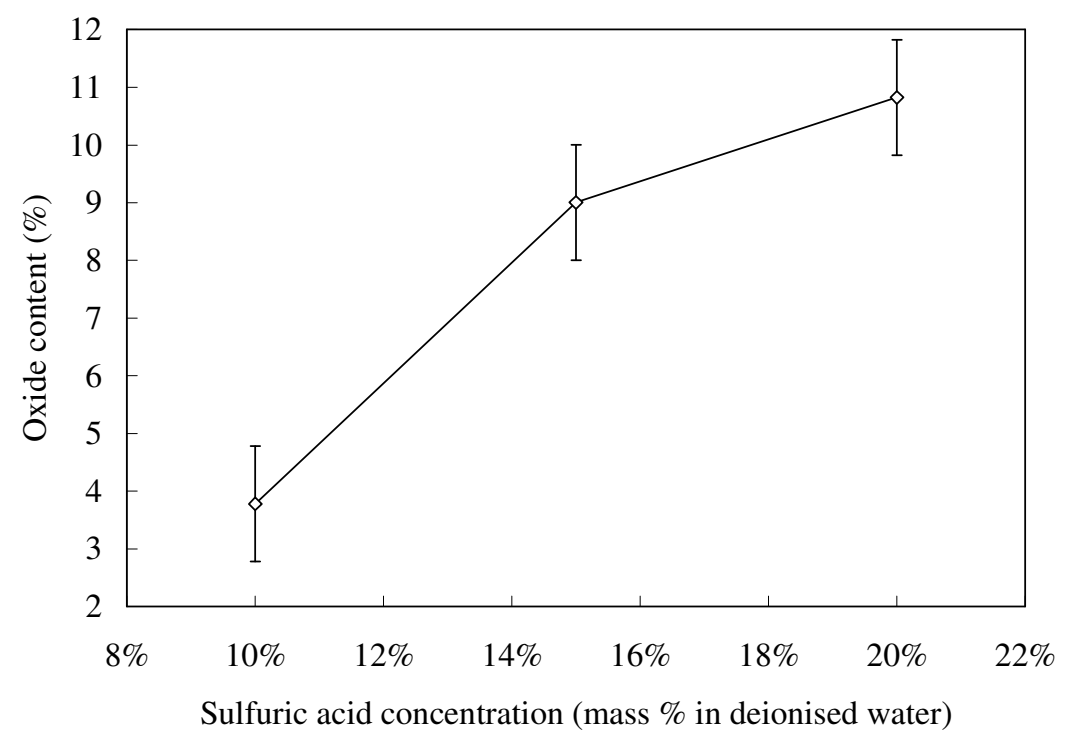

Figure 7. Effect of the acid concentration on the oxide content (20 min, 1.5 A.dm $\left.{ }^{-2}, 30-40 \mu \mathrm{m}\right)$. 


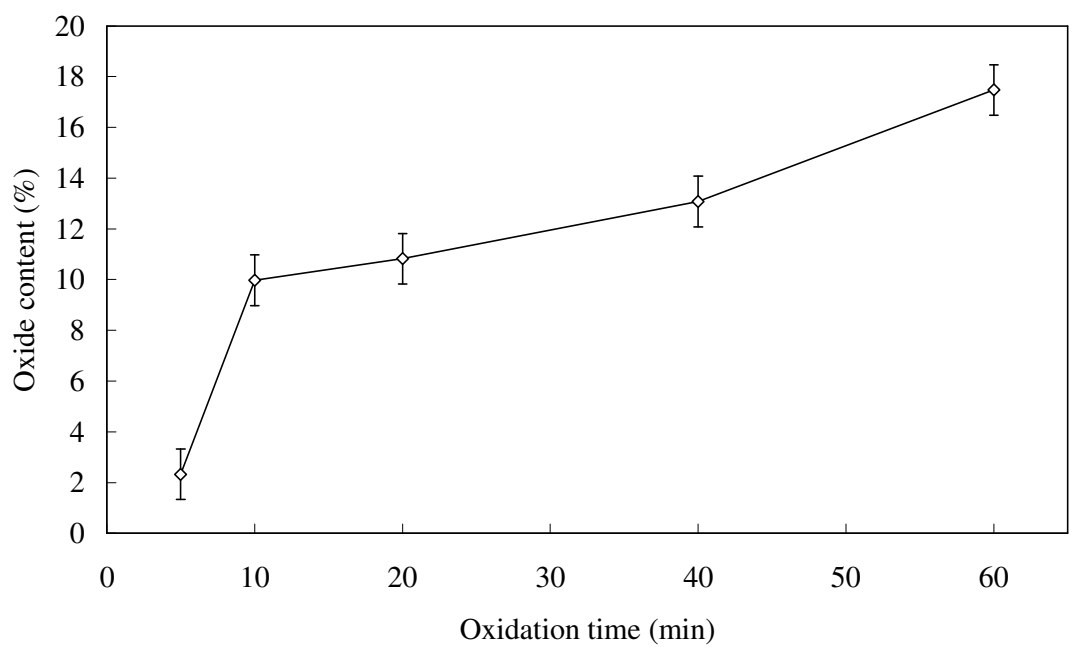

Figure 8. Effect of the time of treatment on the oxide content $\left(1.5{\mathrm{~A} . \mathrm{dm}^{-2}}^{-2}, 20 \%, 30-40 \mu \mathrm{m}\right)$. 


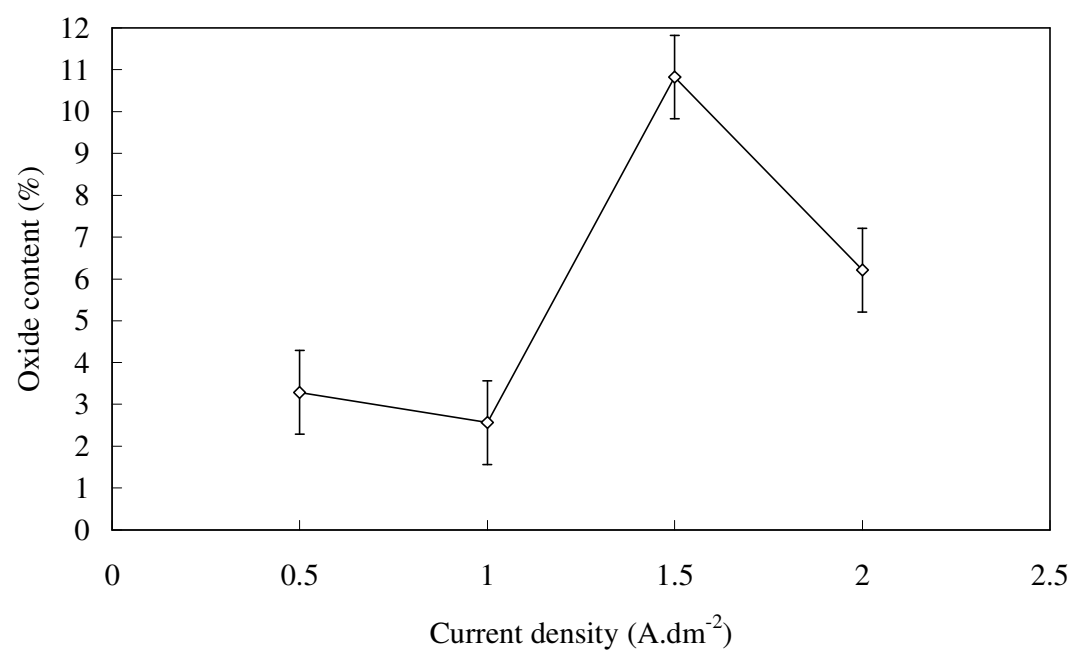

Figure 9. Effect of the current density on the oxide content (20 min, $20 \%, 30-40 \mu \mathrm{m})$. 


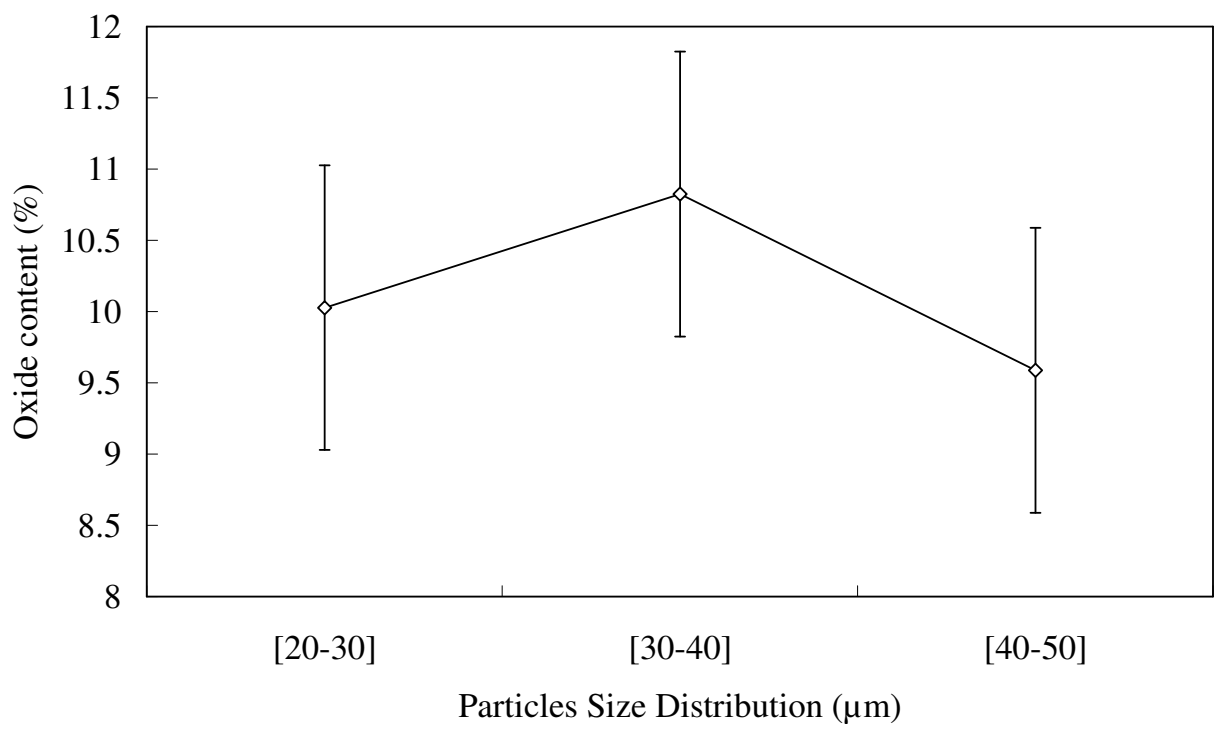

Figure 10. Oxide content of sieved powder treated with the same test parameters $\left(20\right.$ min, $1.5 \mathrm{~A}^{-\mathrm{dm}^{-}}$ ${ }^{2}, 20 \%$ ) - TGA measures. 

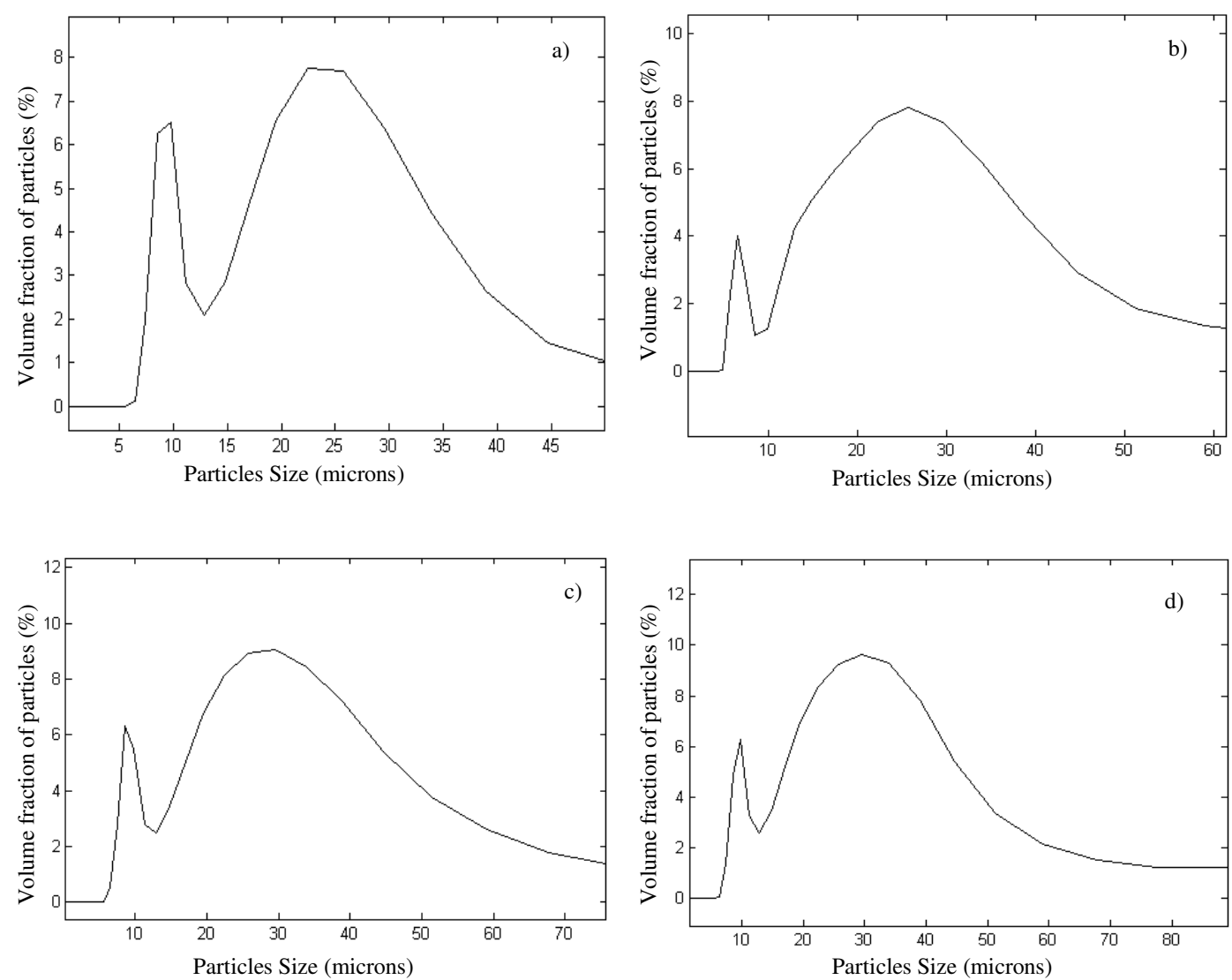

Figure 11. Particles size distribution before (a and c) and after (b and d) the oxidation treatment of sieved powder in the range $20-30 \mu \mathrm{m}$ (a and b) and 30-40 $\mu \mathrm{m}$ (c and d). 


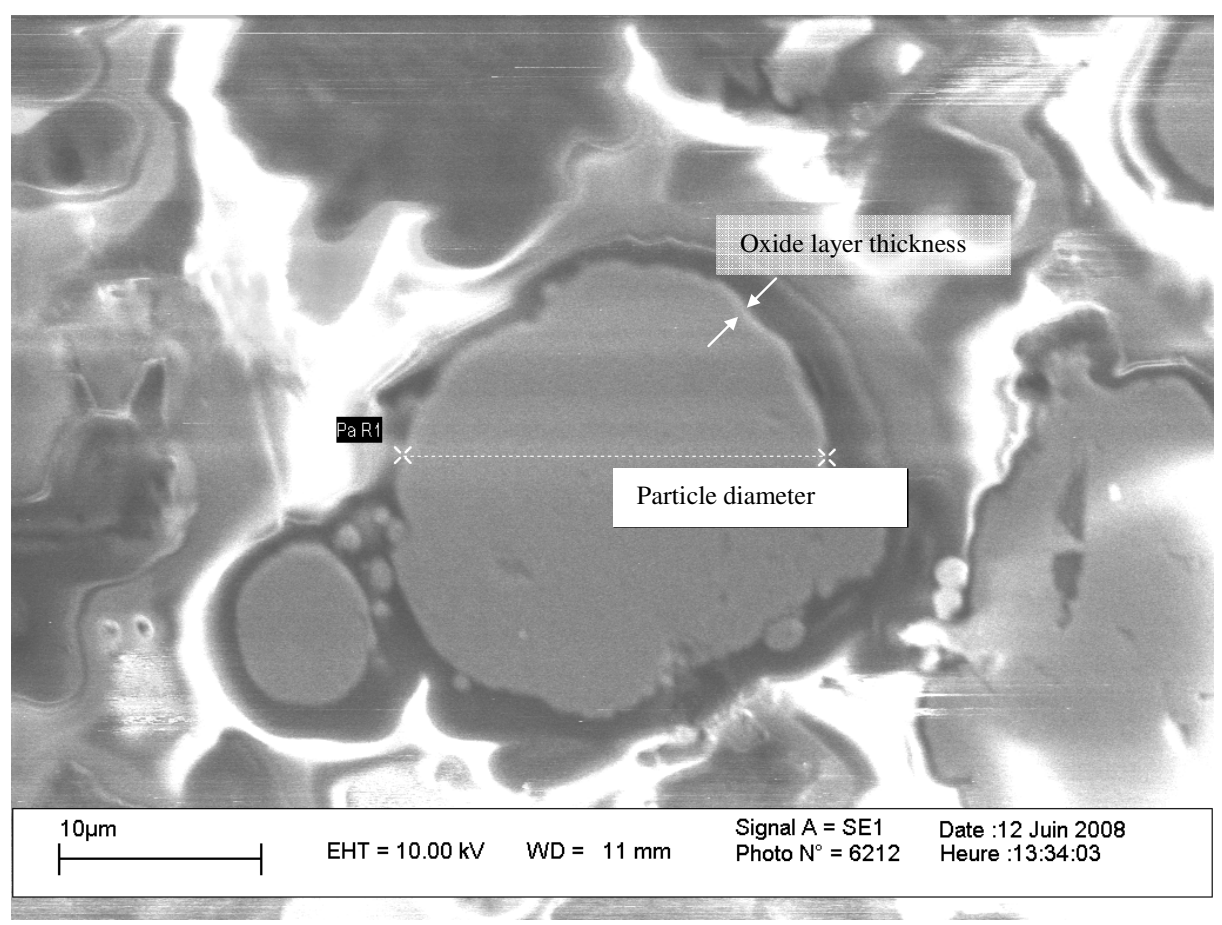

Figure 12. SEM visualisation of Al micrometric particle with oxide layer. 
Table 1. The seven selected parameters for the design of experiment with their two levels.

\begin{tabular}{clcc}
\hline \hline & \multicolumn{2}{c}{ Parameters } & \multicolumn{2}{c}{ Levels } \\
\hline Number & \multicolumn{1}{c}{ Denomination } & Low (-) & High (+) \\
\hline \hline $\mathrm{X}_{1}$ & Time of treatment (min) & 10 & 60 \\
$\mathrm{X}_{2}$ & Electrical current density (A.dm-2) & 0.5 & 2 \\
$\mathrm{X}_{3}$ & Sulfuric Acid concentration (mass \% in water) & 5 & 20 \\
$\mathrm{X}_{4}$ & Particles size distribution (microns) & {$[20-30]$} & {$[40-50]$} \\
$\mathrm{X}_{5}$ & Stirring & without & with \\
$\mathrm{X}_{6}$ & Mass of powder (g) & 5 & 10 \\
$\mathrm{X}_{7}$ & Neutralisation by ammoniac & without & with \\
\hline \hline
\end{tabular}


Table 2. Hadamard matrix of experimental tests with oxide content results and influence of parameters.

\begin{tabular}{cccccccc}
\hline \hline \multirow{2}{*}{$\begin{array}{c}\text { Test } \\
\text { Number }\end{array}$} & \multicolumn{7}{c}{ Number of the parameter } \\
\hline \hline 1 & $\mathrm{X}_{1}$ & $\mathrm{X}_{2}$ & $\mathrm{X}_{3}$ & $\mathrm{X}_{4}$ & $\mathrm{X}_{5}$ & $\mathrm{X}_{6}$ & $\mathrm{X}_{7}$ \\
\hline 2 & - & + & + & - & + & - & - \\
3 & - & - & + & + & - & + & - \\
4 & + & - & - & + & + & + & - \\
5 & - & + & - & - & + & + & + \\
6 & + & - & + & - & - & + & + \\
7 & + & + & - & + & - & - & + \\
8 & - & - & - & - & - & - & - \\
\hline \hline
\end{tabular}

\begin{tabular}{cc}
\hline \hline Results & Oxide content (\%) \\
\hline$Y_{1}$ & $\mathbf{1 5 . 7 7}$ \\
$\mathrm{Y}_{2}$ & $\mathbf{1 0 . 2 9}$ \\
$\mathrm{Y}_{3}$ & $\mathbf{0 . 8 5}$ \\
$\mathrm{Y}_{4}$ & $\mathbf{1 . 5 5}$ \\
$\mathrm{Y}_{5}$ & $\mathbf{2 . 4 4}$ \\
$\mathrm{Y}_{6}$ & $\mathbf{3 . 5 4}$ \\
$\mathrm{Y}_{7}$ & $\mathbf{1 . 8}$ \\
$\mathrm{Y}_{8}$ & $\mathbf{1 . 5}$ \\
\hline \hline
\end{tabular}

\begin{tabular}{ccccccccc}
\hline \hline Effects & $\mathrm{b}_{0}$ & $\mathrm{~b}_{1}$ & $\mathrm{~b}_{2}$ & $\mathrm{~b}_{3}$ & $\mathrm{~b}_{4}$ & $\mathrm{~b}_{5}$ & $\mathrm{~b}_{6}$ & $\mathrm{~b}_{7}$ \\
\hline $\begin{array}{l}\text { Influence of } \\
\text { parameters }\end{array}$ & $\mathbf{3 7 . 7 4}$ & $\mathbf{7 . 5 8}$ & $\mathbf{2 2 . 9 1}$ & $\mathbf{2 3 . 1 6}$ & $\mathbf{- 8 . 7 6}$ & $\mathbf{3 . 4 8}$ & $\mathbf{- 3 . 5 0}$ & $\mathbf{- 2 0 . 4 8}$ \\
\hline \hline
\end{tabular}


Table 3. Determination of the oxide content based on SEM observations.

\begin{tabular}{cccc}
\hline \hline & $20-30 \mu \mathrm{m}$ & $30-40 \mu \mathrm{m}$ & $40-50 \mu \mathrm{m}$ \\
\cline { 2 - 4 } $\begin{array}{c}\text { Particles diameter } \\
(\mu \mathrm{m})\end{array}$ & $21.03 \pm 2.57$ & $17.10 \pm 3.89$ & $23.57 \pm 3.87$ \\
$\begin{array}{c}\text { Oxide layer thickness } \\
(\mathrm{nm})\end{array}$ & $239 \pm 65$ & $311 \pm 109$ & $455 \pm 227$ \\
$\begin{array}{c}\text { Ratio of oxide } \\
\text { thickness on particle } \\
\text { diameter }\end{array}$ & $0.011 \pm 0.005$ & $0.018 \pm 0.014$ & $0.019 \pm 0.016$ \\
Oxide content $(\%)$ & $4.82 \pm 1.78$ & $8.06 \pm 4.12$ & $8.28 \pm 4.86$ \\
\hline \hline
\end{tabular}

